\title{
The B chromosome polymorphism of the grasshopper Eyprepocnemis plorans in North Africa: III. Mutation rate of $B$ chromosomes
}

\author{
M Bakkali ${ }^{1}$ and JPM Camacho \\ Departamento de Genética, Facultad de Ciencias, Universidad de Granada, Granada 18071, Spain
}

\begin{abstract}
B chromosome variation in nine Moroccan populations of the grasshopper Eyprepocnemis plorans was analysed for 3 consecutive years. In addition to $\mathrm{B}_{1}$, which was the predominant $B$ chromosome in all nine populations, we found 15 other B variants, albeit at very low frequency. Eight variants were found in adults caught in the wild, four appeared in adults reared in the laboratory and seven were found in embryo progeny of controlled crosses between a $0 \mathrm{~B}$ male and a B-carrying female. Some variants were found in more than one kind of material. At least the seven $B$ variants that appeared in embryo progeny of females carrying a different $\mathrm{B}$ type arose de novo through mutation of the maternal $\mathrm{B}$ chromosome. The mutation rate of $\mathrm{B}$ chromosomes was $0.73 \%$, on average, which explains the high
\end{abstract}

variety of morphs and banding patterns found. The most frequent de novo mutations observed in these chromosomes were centromere misdivision with or without chromatid nondisjunction, which generates iso-B-chromosomes or telocentric Bs, respectively, as well as translocations with $A$ and $\mathrm{B}$ chromosomes and deletions. But the whole variation observed, including that found in adult individuals, suggests that other mutations such as duplications, inversions and centric fusions do usually affect B chromosomes. Finally, B chromosome mutation rate was remarkably similar in both Moroccan and Spanish populations, which suggests that it might be dependent on $\mathrm{B}$ chromosome intrinsic factors.

Heredity (2004) 92, 428-433, advance online publication, 3 March 2004; doi:10.1038/sj.hdy.6800437

Keywords: B chromosome; Eyprepocnemis plorans; grasshopper; mutation rate; parasitic elements; Orthoptera

\section{Introduction}

Eukaryote genomes are structured in a number of standard chromosomes (A) and, in many species, a variable number of supernumerary, B, chromosomes that behave as genome parasites (Camacho et al, 2000). B chromosomes have been reported in more than 1300 plant and 500 animal species (Jones and Rees, 1982; Jones and Puertas, 1993; Jones, 1995), and Beukeboom (1994) estimated that about $15 \%$ of described living beings harbour polymorphisms for B chromosomes. The nature of these chromosomes is heterogeneous, although they are predominantly heterochromatic and show a high variety of morphologies, chromosomal banding patterns and molecular compositions (Henriques-Gil et al, 1984; Green et al, 1987; Green, 1988; López-León et al, 1993; Bakkali et al, 1999; Cabrero et al, 1999). In Orthoptera, which is the animal group where B chromosome polymorphisms have been more frequently reported (Jones and Rees, 1982), B chromosomes are commonly telocentric, but there are also some iso-B chromosomes originated through centromere misdivision and chromatid nondisjunction, or by centric fusion between two B chromosomes (see López-León et al, 1993).

Correspondence: JPM Camacho, Departamento de Genética, Facultad de Ciencias, Universidad de Granada, Granada 18071, Spain,

E-mail: jpmcamac@ugr.es

${ }^{1}$ Current address: Department of Zoology, the University of British Columbia, 6270 University Boulevard, Vancouver, BC, V6T 1Z4 Canada. Received 3 February 2003; accepted 3 December 2003; published online 3 March 2004
The karyotype of the grasshopper Eyprepocnemis plorans is composed of $2 n=22+X 0$ in males and $2 n=22+X X$ in females. The autosomes may be classified into three size groups: Long $\left(\mathrm{L}_{1}-\mathrm{L}_{2}\right)$, Medium $\left(\mathrm{M}_{3}-\mathrm{M}_{8}\right)$ and Small $\left(\mathrm{S}_{9}-\mathrm{S}_{11}\right)$, the $\mathrm{X}$ chromosome size being intermediate between those of $\mathrm{L}_{2}$ and $\mathrm{M}_{3}$. Previous studies have shown that almost all E. plorans populations analysed from the Mediterranean region and the Caucasus show the polymorphism for B chromosomes (Camacho et al, 1980; Henriques-Gil et al, 1984; LópezFernández et al, 1992; López-León et al, 1993; Cabrero et al, 1997; Bugrov et al, 1999). This polymorphism has revealed the existence of an arms race between $A$ and $\mathrm{B}$ chromosomes leading the system through successive stages with B chromosomes passing from parasitic to near-neutral (Camacho et al, 1997) and vice versa, thus facilitating B-polymorphism regeneration (Zurita et al, 1998). A crucial requisite for this regeneration is a high mutability of $\mathrm{B}$ chromosomes, a property that has been observed in Spanish B chromosomes (López-León et al, 1993).

All North African E. plorans populations hitherto analysed showed the presence of the B chromosome polymorphism. Henriques-Gil and Arana (1990) reported the presence, in Melilla, of a predominant B variant that they named $B_{16}$. Later, Bakkali et al (1999) analysed nine Moroccan populations where the predominant $B$ variant was similar, in morphology and $C$ banding pattern, to the Spanish $\mathrm{B}_{1}$ described by Henriques-Gil et al (1984). The present work analyses the mutability of $\mathrm{B}$ chromosomes in nine Moroccan 
populations of the grasshopper E. plorans, and estimate B chromosome mutation rate in controlled crosses between $\mathrm{B}$-carrying females and $\mathrm{OB}$ males.

\section{Materials and methods}

Adult specimens of the grasshopper E. plorans were collected for 3 consecutive years (1995-1997) at nine natural populations in North-Western Morocco: Smir, Asilah, Larache, Ain l'abid, Tatouft, Frain, SO.DE.A., Mechra Bel Ksiri (to which we call Mechra) and Rabat (see map locations in Bakkali et al, 1999). Most animals were fixed for cytological analysis in Morocco to avoid death risks during transport to Spain. Some specimens caught at Smir, SO.DE.A. and Mechra were taken alive to the laboratory to perform controlled crosses between $\mathrm{B}$-carrying females and $\mathrm{OB}$ males. Live specimens were bred in cages similar to those described in Clemente et al (1985), in a culture room with 10:14 light:dark photoperiod, and $28^{\circ} \mathrm{C}$. Culture conditions were similar to those described in Herrera et al (1996). To facilitate controlled crosses, we performed an in vivo analysis of B chromosome presence in males, which were vivisected for the extraction of some testis follicles by means of a little cut in the median dorsal part of the abdomen. Owing to mortality risks, in vivo study of females was not carried out. For this reason, and to increase the likelihood that females were B-carriers, we firstly obtained a stock of animals with increased B frequency (the progeny of B-carrying males) (see details in Bakkali, 2001; Bakkali et al, 2002). Female virginity in this stock was preserved, for controlled crosses, by separating males and females in the preadult nymph stage. Egg pods were collected from females used in the controlled crosses.

For cytological analysis of adults, testes were fixed in $1: 3$ acetic acid-ethanol and stored at $4{ }^{\circ} \mathrm{C}$, and females were injected with $0.2 \mathrm{ml}$ of $0.05 \%$ colchicine in insect saline solution $6 \mathrm{~h}$ prior to anaesthesia, dissection and extraction of ovaries, which were fixed and stored like testes. For the cytological analysis of embryos, eggs were dissected in insect saline solution, after 11 days of incubation at $28^{\circ} \mathrm{C}$, and embryos were immersed in $1 \mathrm{ml}$ of $0.05 \%$ colchicine in insect saline solution for $45 \mathrm{~min}$. Hypotonic treatment was performed by adding $1 \mathrm{ml}$ of distilled water for $10 \mathrm{~min}$. Finally, embryos were fixed in 1:3 acetic acid-ethanol.

Cytological preparations from adult materials were carried out by squashing two testis follicles (or two ovarioles) in acetic orcein for B presence detection, or in $50 \%$ acetic acid (and then removing the coverslip after freezing in liquid nitrogen) to perform $\mathrm{C}$ banding. Embryo preparations were made by a method similar to that used by Meredith (1969) for the study of mammal meiosis (see details in Camacho et al, 1991). C banding was performed by the technique described in Camacho et al (1984).

To name the different $\mathrm{B}$ chromosome variants found in Morocco, and avoid confusion with the names used in Spain $\left(B_{1}, B_{2}\right.$, etc), we have added an $M$ to the subscript indicating order of finding $\left(\mathrm{B}_{\mathrm{M} 2}, \mathrm{~B}_{\mathrm{M} 3}\right.$, etc). Excepting $\mathrm{B}_{1}$, which was essentially similar to the Spanish one (see Cabrero et al, 1999; Bakkali et al, 2002), coincidence in the classificatory number between Moroccan and Spanish B chromosomes does not necessarily reflect similarity between them. Table 1 shows the equivalence (wherever possible) between Moroccan and Spanish B variants.

Mutation rate was calculated from the de novo origin of $B$ variants in controlled crosses. For this purpose, we scored the number of embryos carrying the maternal $\mathrm{B}$ chromosome as well as those carrying a different $B$ variant. The detectable mutation rate per $\mathrm{B}$ chromosome $\left(u_{\mathrm{B}}\right)$ depends on the total number of embryos analysed. It is calculated as the reciprocal of the product between the total number of embryos analysed $(N)$ and the mean number of Bs found in the sample $\left(M_{\mathrm{B}}\right): u_{\mathrm{B}}=1 /\left(N M_{\mathrm{B}}\right)$. The mutation rate of a $\mathrm{B}$ chromosome is $u_{\mathrm{B}}$ times the number of embryos carrying mutations involving this $B$ chromosome.

\section{Results}

In addition to the principal $\mathrm{B}$ chromosome, $\mathrm{B}_{1}$, the only one present at a relatively high frequency in all Moroccan populations analysed by us (see Bakkali et al, 1999), we found 15 other minority B variants that were distinguishable on the basis of their morphology and $\mathrm{C}$ banding pattern (Figure 1 and Table 1). Eight variants were found in adults caught in the wild, four appeared in adults reared in the laboratory and seven were found in embryo progeny of controlled crosses. As Table 2 shows, some of these variants were found in more than one kind of material. All B variants showed very low frequency, and seven of them (shown in Table 3) were found in embryos whose mother carried a different $B$ variant. The only conceivable mode of origin for these variants is through mutation of the maternal variant, which can be considered the ancestral one.

Several individuals were additionally found to carry chromosomal translocations involving $\mathrm{B}$ and $\mathrm{A}$ chromosomes. An adult male carried a reciprocal translocation between the $\mathrm{B}_{\mathrm{M} 8}$ variant and a mediumsized autosome $\left(\mathrm{M}_{4}\right)$ (see a detailed study in Bakkali et al, 2003), two embryos carried B-A Robertsonian translocations (with the simultaneous observation of a mini-chromosome) and another embryo carried a B-A centric fusion (with no mini-chromosome) (Figure 2). One of the Robertsonian translocations occurred between $B_{1}$ and the $M_{5}$ autosome and the other involved $\mathrm{B}_{\mathrm{M} 3}$ and the smallest autosome $\left(\mathrm{S}_{11}\right)$. The centric fusion occurred between $B_{M 7}$ and the third autosome $\left(\mathrm{M}_{3}\right)$.

The average mutation rate for all types of maternal $\mathrm{B}$ chromosomes analysed in controlled crosses was $0.73 \%$ (Table 4), but there were conspicuous differences between variants, with $\mathrm{B}_{\mathrm{M} 7}$, an isochromosome, being the most unstable $B$ chromosome (9.64\%) giving frequently rise to the $\mathrm{B}_{\mathrm{M} 12}$ variant through centromere misdivision (see Tables 1 and 3) and being involved in a $\mathrm{B}-\mathrm{A}$ translocation (see Figure 2). In total, 20 mutations were found involving B chromosomes, $20 \%$ of which were translocations with A chromosomes, 20\% were translocations between B chromosomes, and the remaining $60 \%$ were mutations involving a single $B$ chromosome. Most single B mutations were centromere misdivisions with or without later chromatid nondisjunction to give rise, respectively, to iso-B-chromosomes (eg $\mathrm{B}_{1}$ becoming $\mathrm{B}_{\mathrm{M} 4}$, or $\mathrm{B}_{\mathrm{M} 3}$ becoming $\mathrm{B}_{\mathrm{M} 13}$ ) 
Table 1 Description and possible origin of the $15 \mathrm{~B}$ chromosome variants found in the six Eyprepocnemis plorans Moroccan populations

\begin{tabular}{|c|c|c|c|c|}
\hline Variant & Description & Ancestral B & $\begin{array}{l}\text { Putative mutations from } B_{1} \text { or the } \\
\text { ancestral B (when known, see Table 3) }\end{array}$ & $\begin{array}{l}\text { Spanish } \\
\text { equivalent }\end{array}$ \\
\hline $\mathrm{B}_{\mathrm{M} 2}$ & $\begin{array}{l}\text { Similar to } B_{1} \text {, with a smaller proximal } \\
C \text { band. Formerly named } B_{1 \mathrm{~d} 1}^{a}\end{array}$ & $\mathrm{~B}_{1}$ & Deletion of satDNA & - \\
\hline $\mathrm{B}_{\mathrm{M} 3}$ & $\begin{array}{l}\text { Same size as } B_{1} \text {, but the interstitial } \\
\text { dark } C \text { band is in a distal location }\end{array}$ & $\mathrm{B}_{1}$ & Paracentric inversion & - \\
\hline $\mathrm{B}_{\mathrm{M} 4}$ & $\begin{array}{l}\text { Iso-B chromosome whose arms are } \\
\text { similar to } B_{1} \text {. Formerly named } B_{1 \text { iso1 }}^{a}\end{array}$ & $\mathrm{~B}_{1}$ & $\begin{array}{l}\text { Centromere misdivision and } \\
\text { chromatid nondisjunction }\end{array}$ & $\mathrm{B}_{12}^{\mathrm{b}}=\mathrm{B}_{1 \text { iso }}^{\mathrm{c}}$ \\
\hline $\mathrm{B}_{\mathrm{M} 5}$ & $\begin{array}{l}\text { Mini-iso-B chromosome whose arms } \\
\text { are similar to } B_{1} \text { short arm. Formerly } \\
\text { named } B_{1 \text { iso2 }}^{a}\end{array}$ & $\mathrm{~B}_{1}$ & $\begin{array}{l}\text { Centromere misdivision and } \\
\text { chromatid nondisjunction }\end{array}$ & - \\
\hline $\mathrm{B}_{\mathrm{M} 6}$ & $\begin{array}{l}\text { It shows an additional dark } C \text { band } \\
\text { and a smaller distal light band. } \\
\text { Formerly named } B_{1 d . d 1}^{a}\end{array}$ & $\mathrm{~B}_{1}$ & $\begin{array}{l}\text { Duplication of satDNA and deletion } \\
\text { of rDNA }\end{array}$ & $\mathrm{B}_{24}^{\mathrm{b}}$ \\
\hline $\mathrm{B}_{\mathrm{M} 7}$ & $\begin{array}{l}\text { Iso-B chromosome with a single dark } \\
\mathrm{C} \text { band in each arm }\end{array}$ & $\mathrm{B}_{1}$ & $\begin{array}{l}\text { Breakage between the two satDNA } \\
\text { blocks and chromatid nondisjunction } \\
\text { with gaining of neocentric activity }\end{array}$ & - \\
\hline $\mathrm{B}_{\mathrm{M} 8}$ & $\begin{array}{l}\text { Same size and } C \text { bands as } B_{M 7} \text { but in } \\
\text { different order }\end{array}$ & $\mathrm{B}_{\mathrm{M} 2}$ & $\begin{array}{l}\text { Breakage between the two satDNA } \\
\text { blocks, gaining of neocentric } \\
\text { activity.and tandem fusion of both } \\
\text { chromatids }\end{array}$ & - \\
\hline $\mathrm{B}_{\mathrm{M} 9}$ & Iso-B chromosome lacking satDNA & Unknown & $\begin{array}{l}\text { Deletion of satDNA and centromere } \\
\text { misdivision with chromatid } \\
\text { nondisjunction }\end{array}$ & - \\
\hline $\mathrm{B}_{\mathrm{M} 10}$ & $\begin{array}{l}\text { Two dark } C \text { bands like those of the } \\
\mathrm{B}_{\mathrm{M} 2} \text { chromosome, and a larger short } \\
\text { arm. The light distal region is shorter. } \\
\text { Formerly named } \mathrm{B}_{\text {1d.et1 }}^{\text {a }}\end{array}$ & $\mathrm{B}_{\mathrm{M} 2}$ & Extra-radial transposition & - \\
\hline $\mathrm{B}_{\mathrm{M} 11}$ & $\begin{array}{l}\text { Two dark } \mathrm{C} \text { bands like those of the } \\
\mathrm{B}_{\mathrm{M} 2} \text { chromosome, and a smaller light } \\
\text { region. Formerly named } \mathrm{B}_{3}^{\mathrm{a}}\end{array}$ & $\mathrm{B}_{\mathrm{M} 2}$ & Partial deletion of most rDNA & $\mathrm{B}_{3}^{\mathrm{b}}$ \\
\hline $\mathrm{B}_{\mathrm{M} 12}$ & $\begin{array}{l}\text { Similar to one arm of the } \mathrm{B}_{\mathrm{M} 7} \\
\text { chromosome }\end{array}$ & $\mathrm{B}_{\mathrm{M} 7}$ & Centromere misdivision & - \\
\hline $\mathrm{B}_{\mathrm{M} 13}$ & $\begin{array}{l}\text { Iso- } B \text { chromosome whose arms are } \\
\text { similar to the } B_{M 3} \text { chromosome }\end{array}$ & $\mathrm{B}_{\mathrm{M} 3}$ & $\begin{array}{l}\text { Centromere misdivision and } \\
\text { chromatid nondisjunction }\end{array}$ & - \\
\hline $\mathrm{B}_{\mathrm{M} 14}$ & $\begin{array}{l}\text { Metacentric chromosome with arms } \\
\text { similar to the } B_{1} \text { y } B_{M 3} \text { chromosomes }\end{array}$ & $\mathrm{B}_{1}$ and $\mathrm{B}_{\mathrm{M} 3}$ & $\begin{array}{l}\text { Robertsonian translocation between } \\
\text { the } B_{1} \text { and } B_{M 3} \text { chromosomes }\end{array}$ & - \\
\hline $\mathrm{B}_{\mathrm{M} 15}$ & $\begin{array}{l}\text { Sub-metacentric chromosome whose } \\
\text { arms are similar to the } B_{\mathrm{M} 2} \text { y } B_{\mathrm{M} 10} \\
\text { chromosomes }\end{array}$ & $\mathrm{B}_{\mathrm{M} 2}$ and $\mathrm{B}_{\mathrm{M} 10}$ & $\begin{array}{l}\text { Robertsonian translocation between } \\
\text { the } \mathrm{B}_{\mathrm{M} 2} \text { and } \mathrm{B}_{\mathrm{M} 10} \text { chromosomes }\end{array}$ & - \\
\hline $\mathrm{B}_{\operatorname{mini}}$ & $\begin{array}{l}\text { Mini-B chromosomes. In this group } \\
\text { are included all the small } \mathrm{B} \\
\text { chromosomes, including } \mathrm{B}_{\mathrm{M} 5}\end{array}$ & $\begin{array}{l}\text { Acrocentric B } \\
\text { chromosomes }\end{array}$ & $\begin{array}{l}\text { Deletions, centromere misdivisions } \\
\text { and Robertsonian translocations }\end{array}$ & $\mathrm{B}_{\operatorname{mini}}^{\mathrm{c}}$ \\
\hline
\end{tabular}

The proximal and interstitial regions of C-banded B chromosomes contain the $180 \mathrm{bp}$ tandem repeat DNA (satDNA) and the distal light region contains ribosomal DNA (rDNA).

aBakkali et al (1999).

bHenriques-Gil et al (1984).

'López-León et al (1993).

or telocentric Bs (eg $B_{\mathrm{M} 7}$ becoming $\mathrm{B}_{\mathrm{M} 12}$ ) (see Tables 3 and 4). The only exception was an embryo from the Smir population carrying $\mathrm{B}_{\mathrm{M} 11}$ presumably arisen from the maternal $\mathrm{B}, \mathrm{B}_{\mathrm{M} 2}$, through deletion of most rDNA (see Figure 1).

\section{Discussion}

On the basis of morphology and $C$ banding pattern, more than $50 \mathrm{~B}$ variants have been described in natural populations of E. plorans (Henriques-Gil et al, 1984; López-León et al, 1993). The $\mathrm{B}_{1}$ chromosome was considered the original $\mathrm{B}$ in Spanish populations (Henriques-Gil et al, 1984). Given its predominance in all nine Moroccan populations analysed, we also considered $\mathrm{B}_{1}$ as the original $\mathrm{B}$ in Moroccan populations (Bakkali et al, 1999). In Melilla, however, the most frequent $\mathrm{B}$ chromosome variant $\left(\mathrm{B}_{16}\right)$, reported by Henriques-Gil and Arana (1990), was different from $B_{1}$. Since this population is separated from the Moroccan populations analysed in Bakkali et al (1999) by the Rif mountains, and from Spanish populations by the Mediterranean sea, it is likely that the B chromosome polymorphism has followed an independent evolutionary pathway in Melilla, although this subject requires further study.

Although $B_{1}$ is well established in all nine populations analysed, our present results show that new B chromosome variants are arising through different mutations, at least in six out of these populations. Bearing in mind that only $\mathrm{B}$ chromosomes showing drive, or being beneficial for the host, are expected to become frequent in natural populations (Camacho et al, 1997), it is likely that most of the rare B variants found in 
Morocco, at very low frequency, are either of very recent origin or else neutral or deleterious (it is reasonable to assume that it is unlikely that a beneficial B variant could appear by mutation of a parasitic B). Since B chromosomes lack a regular meiotic behaviour (they do not go in pairs that pair and segregate during meiosis, as A chromosomes do), a neutral B variant cannot reach fixation by drift, but only be eliminated. In this scenario, the observation of many $B$ variants at low frequency is explained by high mutation rate $(0.73 \%$ on average $)$ compensating loss by drift, although we cannot rule out that any of these rare variants could prosper through drive.

The most frequently observed B mutation was centromere misdivision with chromatid nondisjunction giving rise to iso-B-chromosomes. Translocations with A or B chromosomes were also frequent, most of them implying centromere breakpoints, but only one deletion of rDNA was observed. The complete range of B variants (see Figure 1 and Table 1) suggests that other mutations, such as duplications, inversions and centric fusions, can also affect B chromosomes.

A very similar situation has been reported in Spanish populations, where the de novo formation of $14 \mathrm{~B}$ chromosome variants was found in the progeny of

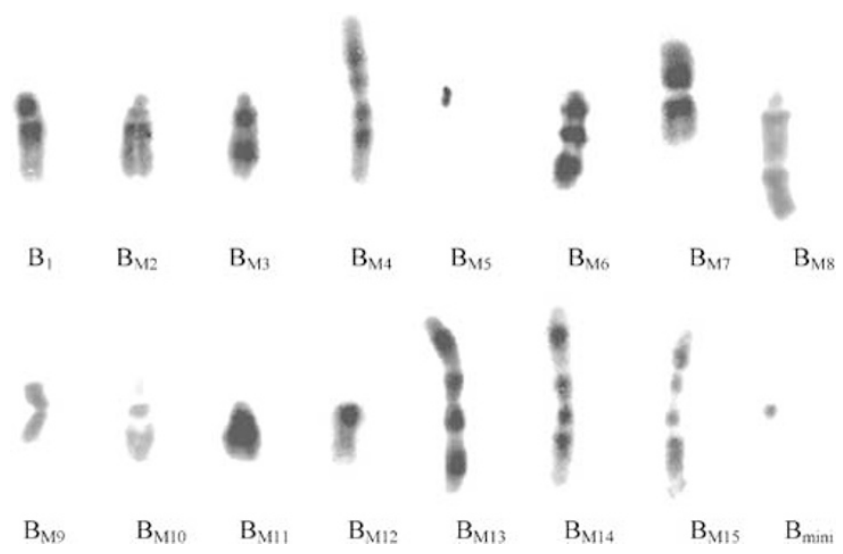

Figure 1 Morphology and C banding pattern of the $16 \mathrm{~B}$ chromosomes found in the nine Moroccan populations studied in this work. $\mathrm{B}_{1}$ is the principal $\mathrm{B}$ chromosome found in all of these populations, the remaining are minority $B$ chromosomes found in some adults from the natural populations or in embryos and adults obtained in our laboratory (see Table 2 ). controlled crosses and gravid females, the formation of iso-B-chromosomes being also the most frequently observed mutation, but tandem and centric fusions, pericentric inversions and deletions were also observed (López-León et al, 1993). Since these 14 B variants were found among a total of 3012 embryos whose average B frequency was 0.787 , the detectable mutation rate per $B$ chromosome was 0.042 in that sample, and the average mutation rate for $\mathrm{B}$ chromosomes (excluding $\mathrm{B}-\mathrm{A}$

Table 3 Frequency of B chromosome variants arisen in controlled crosses performed in the laboratory between a $0 \mathrm{~B}$ male and a B-carrying female

\begin{tabular}{lllc}
\hline $\begin{array}{l}\text { Ancestral B in } \\
\text { the mother }\end{array}$ & $\begin{array}{l}\text { New B } \\
\text { Variant }\end{array}$ & Population & $\begin{array}{l}\text { Embryos carrying } \\
\text { the new B variant }\end{array}$ \\
\hline $\mathrm{B}_{1}$ & $\mathrm{~B}_{\mathrm{M} 4}$ & Smir & 1 \\
$\mathrm{~B}_{1}$ & $\mathrm{~B}_{\mathrm{M} 4}$ & SO.DE.A. & 2 \\
$\mathrm{~B}_{\mathrm{M} 2}$ & $\mathrm{~B}_{\mathrm{M} 11}$ & Smir & 1 \\
$\mathrm{~B}_{\mathrm{M} 7}$ & $\mathrm{~B}_{\mathrm{M} 12}$ & Smir & 7 \\
$\mathrm{~B}_{\mathrm{M} 3}$ & $\mathrm{~B}_{\mathrm{M} 13}$ & SO.DE.A. & 1 \\
$\mathrm{~B}_{1}$ and $\mathrm{B}_{\mathrm{M} 3}$ & $\mathrm{~B}_{\mathrm{M} 14}$ & SO.DE.A. & 1 \\
$\mathrm{~B}_{\mathrm{M} 2}$ and $\mathrm{B}_{\mathrm{M} 10}$ & $\mathrm{~B}_{\mathrm{M} 15}$ & Mechra & 1 \\
$\mathrm{~B}_{1}$ & $\mathrm{~B}_{\mathrm{mini}}$ & SO.DE.A. & 1 \\
$\mathrm{~B}_{\mathrm{M} 2}$ & $\mathrm{~B}_{\text {mini }}$ & Mechra & 1
\end{tabular}

These variants were found in some embryos whose mother carried a different $\mathrm{B}$ chromosome type. Each line refers to a mating of a virgin female to a single $\mathrm{OB}$ male.

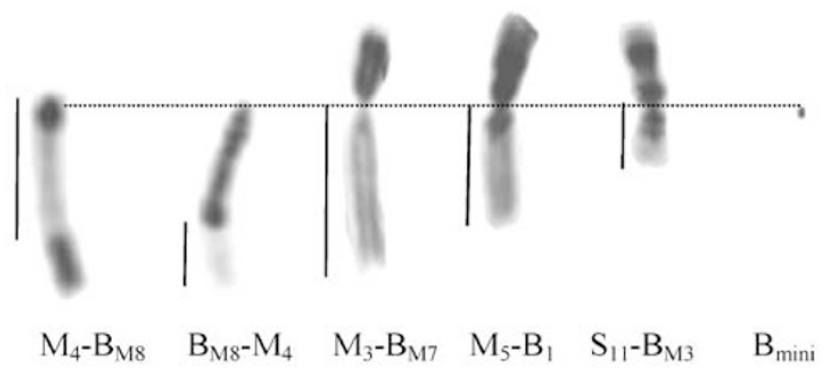

Figure $2 \mathrm{C}$ banding of the chromosomes produced through $\mathrm{A}-\mathrm{B}$ chromosome translocations. $\mathrm{M}_{4}-\mathrm{B}_{\mathrm{M} 8}$ and $\mathrm{B}_{\mathrm{M} 8}-\mathrm{M}_{4}$ were found in and adult male caught at the population of Smir, the remaining had arisen in controlled crosses performed in the laboratory. The dotted line joins the centromeres of all chromosomes. The vertical lines indicate the A chromosome region in each mutant chromosome.

Table 2 Frequency of $10 \mathrm{~B}$ variants found in adult specimens from Moroccan populations of Eyprepocnemis plorans

\begin{tabular}{|c|c|c|c|c|c|c|c|c|c|c|c|c|}
\hline \multirow[t]{2}{*}{ Population } & \multirow[t]{2}{*}{ Year } & \multirow[t]{2}{*}{$\mathrm{N}$} & \multicolumn{10}{|c|}{ Number of specimens carrying the variant: } \\
\hline & & & $B_{M 2}$ & $B_{M 3}$ & $B_{M 4}$ & $B_{M 5}$ & $B_{M 6}$ & $B_{M 7}$ & $B_{M 8}$ & $B_{M 9}$ & $B_{M 10}$ & $B_{M 12}$ \\
\hline Smir & 1997 & 34 & $1^{\mathrm{a}}$ & - & $2^{\mathrm{b}}$ & $2^{\mathrm{b}}$ & $1^{\mathrm{a}}$ & $1^{a}$ & $1^{b}$ & $1^{\mathrm{b}}$ & - & - \\
\hline Ain l'abid & 1997 & 47 & - & - & - & $1^{\mathrm{b}}$ & - & - & - & - & - & - \\
\hline Frain & 1997 & 38 & - & - & - & $1^{\mathrm{b}}$ & - & - & - & - & - & - \\
\hline \multirow[t]{2}{*}{ SO.DE.A. } & 1995 & 34 & - & - & - & - & $1^{\mathrm{b}}$ & - & - & - & - & - \\
\hline & 1997 & 41 & - & $1^{\mathrm{a}}$ & - & - & $3^{b}$ & - & - & - & - & - \\
\hline Mechra & 1996 & 85 & $1^{\mathrm{b}}$ & - & $1^{\mathrm{b}}$ & $1^{\mathrm{b}}$ & - & - & - & - & $1^{\mathrm{b}}$ & - \\
\hline Rabat & 1997 & 16 & - & - & - & - & - & - & - & - & - & $1^{\mathrm{b}}$ \\
\hline
\end{tabular}

$N=$ Number of wild adults examined from the wild.

a Variants found in adult specimens reared in the laboratory.

${ }^{\mathrm{b}} \mathrm{B}$ chromosome variants found in adults caught in the natural population. 
Table 4 Mutation rate of B chromosomes in populations from Morocco, as deduced from the analysis of embryo progeny raised in controlled crosses between a $\mathrm{OB}$ male and a B-carrying female

\begin{tabular}{|c|c|c|c|c|c|c|c|c|c|c|c|c|c|c|c|c|}
\hline \multirow[t]{4}{*}{ Maternal B } & \multirow[t]{4}{*}{ Population } & \multirow[t]{4}{*}{$\mathrm{N}_{c}$} & \multicolumn{4}{|c|}{ Embryo progeny with } & \multirow[t]{4}{*}{$\mathrm{M}_{B}$} & \multirow[t]{4}{*}{$\mu_{B}(\%)$} & \multicolumn{6}{|c|}{ Type of mutation } & \multirow[t]{4}{*}{ Total } & \multirow[t]{4}{*}{ Freq $(\%)$} \\
\hline & & & \multirow[t]{3}{*}{$O B$} & \multirow[t]{3}{*}{$1 B$} & \multirow[t]{3}{*}{$2 B$} & \multirow[t]{3}{*}{$\mathrm{N}_{\mathrm{e}}$} & & & \multicolumn{4}{|c|}{ Translocations } & \multirow{2}{*}{\multicolumn{2}{|c|}{ Single B }} & & \\
\hline & & & & & & & & & \multicolumn{2}{|r|}{$B-A$} & \multicolumn{2}{|r|}{$B-B$} & & & & \\
\hline & & & & & & & & & No. & Freq $(\%)$ & No. & Freq $(\%)$ & No. & Freq $(\%)$ & & \\
\hline \multirow[t]{4}{*}{$\mathrm{B}_{1}$} & Smir & 9 & 420 & 412 & 19 & 851 & 0.529 & 0.222 & & & & & 1 & 0.222 & 1 & 0.222 \\
\hline & SO.DE.A & 6 & 226 & 243 & 2 & 471 & 0.524 & 0.405 & 1 & 0.405 & 1 & 0.405 & 2 & 0.810 & 4 & 1.619 \\
\hline & Mechra & 23 & 616 & 811 & 99 & 1526 & 0.661 & 0.099 & & & & & & & & \\
\hline & Total & 38 & 1262 & 1466 & 120 & 2848 & 0.599 & 0.059 & 1 & 0.059 & 1 & 0.059 & 3 & 0.176 & 5 & 0.293 \\
\hline \multirow[t]{3}{*}{$\mathrm{B}_{\mathrm{M} 2}$} & Smir & 7 & 214 & 436 & 20 & 670 & 0.710 & 0.210 & & & & & 1 & 0.210 & 1 & 0.210 \\
\hline & Mechra & 1 & 40 & 30 & 0 & 70 & 0.429 & 3.333 & & & 1 & 3.333 & & & 1 & 3.333 \\
\hline & Total & 8 & 254 & 466 & 20 & 740 & 0.684 & 0.198 & & & 1 & 0.198 & 1 & 0.198 & 2 & 0.395 \\
\hline $\mathrm{B}_{\mathrm{M} 3}$ & SO.DE.A & 6 & 150 & 409 & 2 & 561 & 0.736 & 0.242 & 2 & 0.484 & 1 & 0.242 & 1 & 0.242 & 4 & 0.969 \\
\hline $\mathrm{B}_{\mathrm{M} 7}$ & Smir & 3 & 107 & 83 & 0 & 190 & 0.437 & 1.205 & 1 & 1.205 & & & 7 & 8.434 & 8 & 9.639 \\
\hline \multirow[t]{2}{*}{$\mathrm{B}_{\mathrm{M} 10}$} & Mechra & 1 & 33 & 37 & 0 & 70 & 0.529 & 2.703 & & & 1 & 2.703 & & & 1 & 2.703 \\
\hline & Total & 56 & 1806 & 2461 & 142 & 4409 & 0.623 & 0.036 & 4 & 0.146 & 4 & 0.146 & 12 & 0.437 & 20 & 0.729 \\
\hline
\end{tabular}

$N_{\mathrm{C}}=$ number of crosses, $N_{\mathrm{e}}=$ total number of embryos analysed, $M_{\mathrm{B}}=$ mean number of $\mathrm{B}$ chromosomes, $\mu_{\mathrm{B}}=$ mutation rate per $\mathrm{B}$ chromosome. The mutations observed were B-A and B-B translocations, and several other mutations involving a single B chromosome.

translocations that were not reported) was $0.59 \%$, a figure being remarkably similar to the observed in Morocco: $0.437+0.146=0.583 \%$ (see Table 4). This similarity suggests that B chromosome mutability depends more on B intrinsic factors than on A-chromosome or environmental factors.

These possible factors might include centromere instability, breakage of repetitive DNA (rDNA or satDNA) and transposable elements. The prevalence of centromere misdivision among the observed chromosome mutations suggests that centromere is the most unstable region in the E. plorans B chromosomes. This instability might derive from its heterochromatic nature and/or the presence of repetitive DNA in its vicinity, that is, the $180 \mathrm{bp}$ sat DNA (López-León et al, 1994, 1995). This would be consistent with the finding that centromere is a repeated structure that can be split into smaller fragments that are still able to work properly (Zinkowski et al, 1991). In maize, the size of B-chromosome centromeres, produced by misdivision, is strongly correlated to meiotic transmission and the presence of B-specific DNA repeats in the centromere (Kaszás and Birchler, 1996, 1998). However, it is also possible that centromere propensity to breakage is associated to the presence of mobile elements, which have been shown to be frequent in B chromosomes, for example, in Nasonia vitripennis (McAllister, 1995). Preliminary data, however, suggest that mobile elements such as Gypsy and Mariner are absent from repetitive DNA and centromeric regions of E. plorans B chromosomes (López-León et al, unpublished), although it does not rule out the possible implication of other unknown elements associated to B centromere instability. In fact, Gypsy and Mariner are located between the satDNA blocks in Spanish $\mathrm{B}_{1}, \mathrm{~B}_{2}$ and $\mathrm{B}_{24}$ and, remarkably, the Moroccan $\mathrm{B}_{\mathrm{M} 7}$ arose by breakage at this level presumably followed by neocentric activity, which may be associated to the presence of repetitive DNA (Alfenito and Birchler, 1993; Manzanero et al, 2002).

The high mutability of E. plorans B chromosomes is tolerated because of their dispensable nature, but it promotes their evolution by increasing the likelihood of generating new parasitic variants and thus constitutes one of the main B-chromosome weapons in their evolutionary arms race with $A$ chromosomes (Camacho et al, 1997). Our present work suggests that this high mutability is most likely due to B-chromosome intrinsic factors, the nature of which will be the subject for future research.

\section{Acknowledgements}

M Bakkali thank the Universities of Abdelmalek Essaadi (Morocco) and Granada (Spain), the 'Agencia Española De Cooperación Internacional, Instituto de Cooperación con el Mundo Arabe, Mediterráneo y Paises en Vias de Desarrollo' (Spain) and the 'Ministère de l'Enseignement Supérieur, de la Formation des Cadres et de la Recherche Scientifique' (Morocco) for conceding studentships. We thank Mr Soulaïmane Bakkali for his help in capturing specimens. This study was supported by grants from the Spanish Ministerio de Ciencia y Tecnología (BOS20001521) and Plan Andaluz de Investigación, Grupo no. CVI-165.

\section{References}

Alfenito MR, Birchler JA (1993). Molecular characterization of a maize B chromosome centric sequence. Genetics 135: 589-597.

Bakkali M (2001). Evolución de los cromosomas B del saltamontes Eyprepocnemis plorans en Marruecos. PhD thesis. Universidad de Granada: Spain.

Bakkali M, Cabrero J, López-León MD, Perfectti F, Camacho JPM (1999). The B chromosome polymorphism of the 
grasshopper Eyprepocnemis plorans in north Africa. I. B variants and frequency. Heredity 83: 428-434.

Bakkali M, Cabrero J, Camacho JPM (2003). B-A interchanges are an unlikely pathway for B chromosome integration into the standard genome. Chromosome Res 11: 115-123.

Bakkali M, Perfectti F, Camacho JPM (2002). The B-chromosome polymorphism of the grasshopper Eyprepocnemis plorans in North Africa: II. Parasitic and neutralized B1 chromosomes. Heredity 88: 14-18.

Beukeboom LW (1994). Bewildering Bs: an impression of the 1st B-Chromosome Conference. Heredity 73: 328-336.

Bugrov A, Warchalowska-Śliwa E, Vysotskaya L (1999). Karyotypic features of Eyprepocnemidinae grasshoppers from Russia and Central Asia with reference to the B chromosomes in Eyprepocnemis plorans (Charp). 47: 97-104.

Cabrero J, López-León MD, Bakkali M, Camacho JPM (1999). Common origin of $\mathrm{B}$ chromosome variants in the grasshopper Eyprepocnemis plorans. Heredity 83: 435-439.

Cabrero J, López-León MD, Gómez R, Castro AJ, MartínAlganza A, Camacho JPM (1997). Geographical distribution of $\mathrm{B}$ chromosomes in the grasshopper Eyprepocnemis plorans, along a river basin, is mainly shaped by non-selective historical events. Chromosome Res 5: 194-198.

Camacho JPM, Carballo AR, Cabrero J (1980). The B chromosome system of the grasshopper Eyprepocnemis plorans sub. plorans (Charpentier). Chromosoma 80: 163-166.

Camacho JPM, Cabrero J, Viseras E, López-León MD, NavasCastillo J, Alché JD (1991). G-banding in two species of grasshoppers and its relationship to $\mathrm{C}, \mathrm{N}$ and fluorescence banding techniques. Genome 34: 638-643.

Camacho JPM, Viseras E, Navas J, Cabrero J (1984). C-heterochromatin content of supernumerary chromosome segments of grasshoppers: detection of an euchromatic extra segment. Heredity 53: 167-175.

Camacho JPM, Shaw MW, López-León MD, Pardo MC, Cabrero J (1997). Population dynamics of a selfish B chromosome neutralized by the standard genome in the grasshopper Eyprepocnemis plorans. Am Nat 149: 1030-1050.

Camacho JPM, Sharbel TF, Beukeboom LW (2000). B chromosome evolution. Philos Trans Roy Soc London B 355: 163-178.

Clemente ME, García MD, Presa JJ (1985). Estudio sobre la biología en cautividad de Caelifera (Insecta, Orthoptera). In: Gosálvez J, López-Fernández C, García de la Vega C (eds) Orthoptera. Vol 1. UAM: Madrid, pp. 256-261.

Green DM (1988). Cytogenetics of the endemic New Zealand frog, Leiopelma hochstetteri: extraordinary supernumerary chromosome variation and a unique sex-chromosome system. Chromosoma 97: 55-70.

Green DM, Kezer J, Nussbaum RA (1987). Supernumerary chromosome variation and heterochromatin distribution in the endemic New Zeland frog, Leiopelma hochstetteri. Chromosoma 95: 339-344.
Henriques-Gil N, Arana P (1990). Origin and substitution of B chromosomes in the grasshopper Eyprepocnemis plorans. Evolution 44: 747-753.

Henriques-Gil N, Santos JL, Arana P (1984). Evolution of a complex polymorphism in the grasshopper Eyprepocnemis plorans. Chromosoma 89: 290-293.

Herrera JA, López-León MD, Cabrero J, Shaw MW, Camacho JPM (1996). Evidence for B chromosome drive suppression in the grasshopper Eyprepocnemis plorans. Heredity 76: 633-639.

Jones RN (1995). Tansley review no. 85: B chromosomes in plants. New Phytol 131: 411-434.

Jones RN, Puertas MJ (1993). The B-chromosomes of rye (Secale cereale L). In: Dhir KK, Sareen TS (eds) Frontiers in Plant Science Research. Bhagwati Enterprises: Delhi, pp 81-112.

Jones RN, Rees H (1982). B Chromosomes. Academic Press: New York.

Kaszás É, Birchler JA (1996). Misdivision analysis of centromere structure in maize. EMBO J 15: 5246-5255.

Kaszás É, Birchler JA (1998). Meiotic transmission rates correlate with physical features of rearranged centromeres in maize. Genetics 150: 1683-1692.

López-Fernández C, Mezzanotte R, Gosálvez J (1992). Autosomal, sex and B chromosomes in Eyprepocnemis plorans (Orthoptera) viewed with restriction endonuclease in situ digestion. Heredity 68: 365-372.

López-León MD, Cabrero J, Pardo MC, Viseras E, Camacho JPM, Santos JL (1993). Generating high variability of B chromosomes in the grasshopper Eyprepocnemis plorans. Heredity 71: 352-362.

López-León MD, Neves N, Schwarzacher T, Heslop-Harrison TS, Hewitt GM, Camacho JPM (1994). Possible origin of a B chromosome deduced from its DNA composition using double FISH technique. Chromosome Res 2: 87-92.

López-León MD, Vázquez P, Hewitt GM, Camacho JPM (1995). Cloning and sequence analysis of an extremely homogeneous tandemly repeated DNA in the grasshopper Eyprepocnemis plorans. Heredity 75: 370-375.

Manzanero S, Vega JM, Houben A, Puertas MJ (2002). Characterization of the constriction with neocentric activity of 5RL chromosome in wheat. Chromosoma 111: 228-235.

McAllister BF (1995). Isolation and characterisation of a retroelement from B chromosome (PSR) in the parasitic wasp Nasonia vitripennis. Insect Mol Biol 4: 253-262.

Meredith R (1969). A simple method for preparing meiotic chromosomes from mammalian tests. Chromosoma 26 254-258.

Zinkowski RP, Meyne J, Brinkley BR (1991). The centromerekinetochore complex: a repeat subunit model. J Cell Biol 113: 1091-1110.

Zurita S, Cabrero J, López-León MD, Camacho JPM (1998). Polymorphism regeneration for a neutralized selfish B chromosome. Evolution 52: 274-277. 